NASA Technical Memorandum 83044

\title{
Hygrothermomechanical Evaluation of Transverse Filament Tape Epoxy/Polyester Fiberglass Composites
}

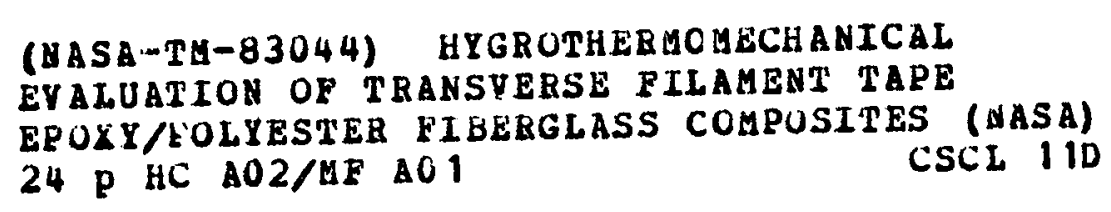

N83- 15362

R. L. Lark and C. C. Chamis

Lewis Research Center

Cleveland, Ohio

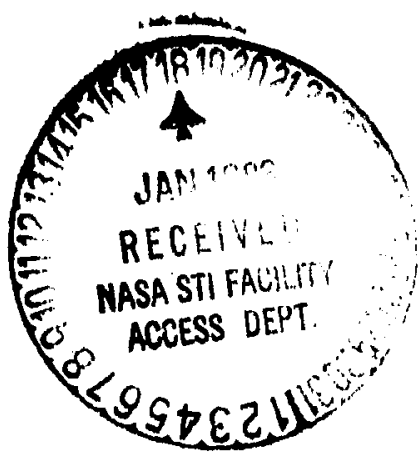

Prepared for the

Thirty-eighth Annual Conference of the

Society of Plastics Industry (SPI)

Reinforced Plastics/Composites Institute

Houston, Texas, February 7-11, 1983 


\title{
HYGROTHERMUME CHANICAL EVALUATION OF TRANSVERSH FILAMENT TAPE EPOXY/POLYESTER FIBERGLASS COMPOSITES
}

\author{
R. F. Lark* and C. C. Chamis** \\ National Aeronautics and Space Administration \\ Lewis Research Center \\ Cleveland, Ohio 44135
}

\begin{abstract}
The static and cyclic load behavior of transverse filament tape (TF') fiberglass/epoxy and TFT fiberglass/polyester composites, intended for use in the design of low-cost wind turbine blades, are presented. The data behavior is also evaluated with respect to predicted properties based on an integrated hygrothermomechanical response theory.

Experimental TFT composite data were developed by the testing of laminates made by using composite layups typical of those used for the fabrication of TFT fiberglass wind turbine blades. Static properties include tension, compression, and interlamina: shear strengths at anbient conditions and at high humidity/elevated temperature conditions after a 500 hour exposure. Cyclic fatigue data were obtained using similar environmental conditions and a range of cyclic stresses.

The environmental (temperature and moisture) and cyclic load effects on composite strength degradation are subsequently compared with the predictions obtained by using the composite life/durability theory developed at NASA-Lewis. The results obtained show that the predicted hygrothermomechanical environmental effects on TFT composites are in good agreement with measured data for various properties including fatigue at different cyclic stresses. The results obtained also demonstrate that the integrated hygrothermomechanical and fatigue life theories can be used to analyze and assess TFT composites with relatively little experimental data.
\end{abstract}

\subsection{INTRODUCTION}

The objective of this paper is to compare the experimental and predicted static and cyclic fatigue properties of both transverse filament tape (TFT) TFT/epoxy and TFT/polyester composites. The experimental data were developed by the testing of flat TFT lamintes made by using composite layups typical of those used for the fabrication of TFT fiberglass wind turbine blades. Static properties developed include tension, compression, and interlaninar shear strengths at ambient room condition and at high humidity/elevated temperature conditons after a 500 hour exposure. Cyclic fatigue data were obtained using similar environmental conditons over a range of R-ratios (max. to min. cyclic applied siress). The experimental fiberglass TFT data sumnarized in this report were obtained under a Department of Energy/NASA-Lewis Research Center program (ref. 1).

* Hrospace Engineer.

* Aerospace Structures and Composites Engineer. 
The degradation effects of both moisture and temperature on the properties of TFT composites were analyzed by using an integrated theory to predict the hygrothermomechanical response of advanced fiber composite laminates The theory was developed at NASA-Lewis, and is described in reference 2. Briefly this theory determines the mosture, thermal and mechanical load (hygrothermomechanical) response of a composite structure by integrating composite micro and macro mechanics, combined-stress failure criteria, 1 aminate theory and advanced structural mechanics analys is programs: This integrated theory and other recent developments were used to predict the effects of hygrothermal environments on the properties of TFT/epoxy (TFT/E) and TFT/polyester (TFT/P) composite laminates and thereby assess the ir behavior ir these environments. Comparisons of experimental data versus prediced TFi composite properties, based on hygrothermomechanical anaiysis, are presented and discussed.

\subsection{COMPOSITE MATERIALS ANO TEST SPECIMENTS}

The composite lamintes evaluated in this report were fabricated under a DOE/NASA Contract for the design and fabrication of 60-foot fiberglass wind turbine blades (ref. 3 ). One of the tasks in this contract was to design and make flat TFT iaminates for the preparation of test speciments to provide baseline static and cyclic fatigue properties for the design of future TFT fiverglass blades. The preparation and testing of the TFT specimens was accomplished under a related DOE/NASA contract (ref. 1).

\subsection{TFT Laminate and Specimen Descriptinn}

The transverse filament tape (TFT), used to make laminates, was in the form of 7-inch wide tape made from transverse bundles of E-glass fibers. The fiber bundles were supported by continuous carrier threads running transverse to the glass fiber bundles. The flat TFT laminates were made by wrapping resin-impregnated TFT materials over a rotating flat mandrel as shown schematically in figure 1. The TFT tape materials were wound using a 3-inch overlap, the same overlap used for construction of the 60-foot Mod-0A ( $200 \mathrm{~kW}$ wind turbine with a $120 \mathrm{ft}$ diam rotor) blades (ref. 3 ).

Balanced symmetric laminates were made using two differnt winding patterns or ply configurations, as shown on table $I$. Winding Patern 1 was a $0^{\circ}$ and $90^{\circ}(0 / 90)$ laminate configuration and simulated the prttern used for the fabrication of the experimental 150-foot TFT fiberglass wind turbine blade (ref. 4). Winding Pattern 2 was a $0^{\circ}, 90^{\circ}$, and $+45^{\circ}(0 / 90 /+45)$ laminate configuration used for the fabrication of the 60-foot TFT Mod-OA blades. The TFT laminates also contain longitudinal filament tape (LFT) for compaction of the TFT plies and biased filament tape (BFT) for torsional stiffness in accordance with the blade design requirements.

TFT laminates were made using Winding Patterns 1 and 2 and an epoxy res in that was used for the fabrication of the 60 and 150 foot blades. TFT laminates were also made using Winding Pattern 2 and a low-cost polyester resin system.

After the laminates were wound on the mandrel, the mandrel and the uncured TFT composite windings were removed from the winding machine and sandwiched between two flat caul plates supported on a fixture. The uncured laminates were cut around the ends of the mandrel at this time to preclude the formation of curvature in the laminate during curing 
lhe: fixture was placod in all oven held at a $200^{\circ} f$. Pressure wos appliond to the caul plate/laminate assembly by using a vacuum hag system that siml-lated the vacum compaction used for fabrication of the bio-foot blales. After curing of the flat laminates was completed, the laminates were trimmed and subjected to an ultrasonic: c-scan inspection. The results of the ultrasonic tests indicated that the laminates were of good quality and were suit.able for the preparation of specimens.

\subsection{Test Speciment Genmety}

The laninates were cut into tension, compression, and interlaminar shear specimens in accordance with the specimen geometry shown in figure 2. The tension specimen shown in figure 2 is a straight-sided, flat specimen similar to the type used for the testing of advanced composite materials. Fiberglass doubler tabs were adhesively bonded to both sides of the specimens. The specimens were environmentally conditioned and then equipped with foil-type strain gages located at the center of the specimens.

\subsection{Environmental Conditioning of Specimens}

The environmental conditioning of specimens was accomplished as follows: For the room temperature dry condition (RTD), specimens were dried in an oven at $120^{\circ} \mathrm{F}$ for 6 hours, cooled to room temperature $\left(70^{\circ} \mathrm{F}\right)$ and heid in a laboratory-type desicator until ready for testing. Both static and cyclic fatigue tests were conducted in the RTD condition.

Wet conditions were attained by placing RTD-conditioned specimens in an oven at $120^{\circ} \mathrm{F}$. , and suspending but not inmersing them over water for a period of 500 hours. One series of specimens was wet conditioned for a period of 4,000 hours. The weight gain after 500 hours was negligible, while the weight gain after the 4,000 hour exposure was about 2-percent by weight.

Environmental control during the static tests was accomplished by using an enclosed oven with a pan of water at the hottom to provide moisture. The wet fat igue tests were conducted in a enclosed environmental chamber. A detailed description of this chamber and the technique for testing imultiple specimens simultaneously are presented in reference 5.

\subsection{STATIC AND CYCLIC FATIGUE TESTING AND RESULIS}

The static and cyclic ratigue test program is summarized in table 11. The cyclic fatique test schedule included R-values (ratio of min. to max, cyclic stress) ranging from 0 to -1.0. Because of the compressive stress imposed during the reversed portion of the tension test, the cyclic fatigue specimens were supported to prevent buckling by using bending stabilization fixtures. As noted in a previous section, the cyclic load (fatique) tests were conducted in an environnental chamber that had the capability of testing five "pecimens simultaneously. Figure 3 shows a view of the test chamber with the top cover removed. The tixtures for multiple specimen testing can be seell inside the chaniber. Fiqure 4 shows a view of the mult iple specimen testing chain equipped with individual specimen stabilization fixtures.

fan-induced airf low was provided across the specimens during cyclic $t$ at igue testing at $30 \mathrm{~Hz}$ to control specimen temperatures. Specimen temperatures did not exceed $78^{\circ} \mathrm{F}$ for ambient conditions and $10^{\circ} \mathrm{F}$ for the elevated temperature/humidity condition. 


\subsection{Static Tost Results}

A summary of the average mechanical properties of the three TFi laninate types is listed in table IIJ. Observations derived from the test. results are as follows:

1. Tensile and compression strengths of the TFT/epoxy composile's with Winding Pattern 1 are about 10-percent higher than the Winding Patlern : TFT/epoxy composites.

2. The tensile and conpressive moduli of the Winding Pattern I TFT/epoxy composites are about 20-percent higher than the Winding Pattern 2 TFT/epoxy composites as expected since Winding Pattern 2 has \pm 45 -degree plies in addition to $0 / 90$ degree plies.

3. No significant difference in interlaminar shear strength was noted beiween resin systems and winding patterns.

4. The tensile and compressive strengths of the TFT/piayester composites were slightly lower than the Winding Pattern 1 TFT/epoxy composites. The moduli of the TFT/polyester composites were closer to the moduli values for the Winding Pattern? TFT/epoxy composites.

5. The static strengths of the TFT/polyester composites are higher than the corresponding strengths of the TFT/epoxy composites having the sane winding pattern.

6. There appear to be no significant differences between wet and dry strengths and moduli for the Winding Pattern I TFT/epoxy composites. There appears to be a mixed behavior for Winding Pattern ? TFT/epoxy composites, but on an overall basis there is an insignificant difference between wet and dry strength values.

7. The wet interlaminar shear strengths for both winding patterns of the TFT/epoxy composites were sianificantily higher than the corresponding dry values.

8. There was about a 25-percent decreas: in the strengths of the TFT/polyester composites which were exposed for 4,000 hours at 98-percent: relative himidity, compared to the corresponding dry strength properties

9. The composite moduli (dominated by longitudinal fiber properties) were nut significantly affected by moisture.

Typical views of factured specimens are shown in figures 5 to 7.

\subsection{Cyclic Fatigue Test Results}

A summary of the tension-tension stress versus number of cycles to failure $(S-N)$ curve's $(R=0)$ for the Winding Patterns 1 and ? TFT/epoxy composites are shown in figures 8 and 9 , respectively. Sone reduction in the wet cyclic fatigue strengths was indicated for the Winding Pattern 1 TF T/epoxy composites. The wet cyclic fatigue strengths were not determined 
for all values of stress for the Winding Pattern 2 TFT/epoxy composites, but the values obtained for a $14.5 \mathrm{ks}$ i stress range appeared to be part of the same S-N (stress versus number of cycles) curve. Thus the fatigue data for both dry and hygrothermal cases appear to coalesce at high fatigue cycles ( $N$ greater than $10^{6}$ ).

The cyclic fatigue lines are plotted in figure 10 for various values of the stress range (S-max. - S-min.) for the Winding Pattern 1 TFT epoxy composites. The data in figures 8 to. 10 were used to construct a modified Goodman plot shown in figure 11. The modified Goodman plot can be used for the design of TFT fibergiass wind turbine blades and other structural components. The curves shown in figure 11 are similar to those obtained for other common aerospace materials such as metals, plastics, and composites.

\subsection{HYGROTHERNIOMECHANICAL ANALYSIS, RESULTS AND COMPARISIONS}

A hygrothermomechanical analysis was performed to predict the environmental effects on the properties of the TFT composites. The predictions are based on the theories described in reference 2. The predictions include unidirectional properties of the TFT, properties of the laminates with Winding fatterns 1 and 2, thermal and hygral ply stresses, laminate strength, fatigue strength and attendant environmental effects. These are described below.

\subsection{Unidirectional Composite Properties}

The predicted properties of the unidirectional composites needed for hygrothermomechanical analys is (NO.transverse filaments) are summarized in table IV for TFT/ epoxy (TFT/E) and TFT/polyester (TFT/P). These properties are for RTD conditions. The properties in this table were not previously available. They were determined analytically from the measured properties given in table III and composite micromechanics using typical properties for E-glass fiber, epoxy and polyester resin, for example, thermal expansion coefficients, moisture expansior coefficients, tensile strength, and glass transition temperature. The properties used from table III were modulus, Poisson's ratio, tensile strength, compressive and interlaminar shear strengths for Winding Pattern 1 only These properties were used with composite micromechanics to back calculate the corresponding matric (epoxy and polyester) properties and the fiber volume ratio. Subsequentiy, these resin properties were used with composite micromechanics to determine the first 15 properties listed in table IV. The ply thickness was determined from the measured laminate thickness and the winging patterns summarized in table 1.

\subsection{TFT Composite Properties}

The TFT composite properties used in the hygrothermomechanical analys is are summarized in table $V$. The properties listed in this table were determined using laminate theory (ref. 6) and the unidirectional composite properties in table IV. The predicted modulus $\left(E_{C \times x}\right)$ values in table $V$ are within 7-percent of the average of the corresponding moduli in table III. This is considered to be a very good agreement since most of the unidirectional properties needed for these calculations were determined using composite micromechanics, as mentioned previously. The predicted 
values of the Poisson's ratios in table $V$ are about 30-percent smaller than the average of the corresponding values in table III. This indicated that the $0^{\circ}$ plies and the $+45^{\circ}$ plies do not provide as much transverse restraint in a uniaxial test compared to the restraint inherent in the laminate theory.

\subsection{Ply Thermal Stresses}

The ply thermal stresses were determined using laminate theory. Laminate theory requires ply properties, composite (laminate) properties and the respective change in temperature $(\Delta T)$. The ply and laminate properties are tabulated in tables IV and $V$, respectively. The change in temperature $(\Delta T)$ was the difference in use-temperature $\left(120^{\circ} \mathrm{F}\right)$ minus the cure temperature $\left(70^{\circ} \mathrm{F}\right)$ or $\Delta T$ equals $50^{\circ} \mathrm{F}\left(120^{\circ}-70^{\circ} \mathrm{F}\right)$ for the environmental conditions in table III. Of the three ply thermal stresses (longitudinal, transverse, and shear), the transverse is usually the most critical since this stress causes transply cracks when it is tensile. The transverse ply thermal stresses were compressive in the $0^{\circ}, 90^{\circ}$, and $\pm 45^{\circ}$ plies for both composite systems and for both winding patterns. The maximum magnitude in the $+45^{\circ}$ plies was about -600 psi which was only about 3 -percent of the corresponding ply transverse compressive strength $\left(S_{l 22 c}=20,000\right.$ psi) in table IV. The conclusion from the thermal stress analysis is that the thermal stresses are negligible in TFT/E and TFT/P laminates for a temperature change of $50^{\circ} \mathrm{F}$.

\subsection{Ply Hygral Stresses}

The ply hygral stresses were also deterinined using laminate theory with ply properties (table IV), laminate properties (table $V$ ) and the respective moisture change. The moisture change equals the moisture pick-up from a reference cundition, usually room temperature dry. The moisture change is about i-percent for the environmental conditions in table III. The ply transverse hygral stresses are the most critical since these could cause transply cracks, as was the case for the thermal stresses. The prediciced ply transverse hygral stresses are compressive and about $-1,500$ psi which is about 8-percent of the corresponding ply transverse compressive strength $S_{l 22 c}=20,000$ psi) in table IV. The conclusion from the ply hygral stress analysis is that the hygral stresses are negligible in both winding patterns and both composite systems for the 2-percent moisture environmental condi- tion. It is interesting to note that the ply hygral stresses are about twice the corresponding thermal stress.

\subsection{Laminate Static Strength}

The laminate static strength was predicted using laminate theory in conjunction with ply stress influence coefficients (ref.7). Both ply (table IV) and laminate (table V) properties are needed to determine laminate strength using the ply stress influence coefficients. Laminate strength is determined for three different conditions: (1) room temperature dry (RTD), (2) with a hygrothermal environment (HT-ENV.) and (3) hygrothermally degraded (HT-degraded). Laminate strengths were determined for TFT/E Winding Patterns 1 and 2 , and TFT/P for Winding Pattern 2 (corresponding to the experimental data in table III). The HT-degraded properties were determined using the procedure (ref.8): (1) an empirical equation to 
estimate the glass transition temperature of a wet composite $\left(T_{g w}\right)$ is as follows:

$$
T_{g w} / i_{g 0}=0.01 M^{2}-0.1 M+1
$$

where $T_{\text {gt }}$ is the glass transition temperature of the dry (reference) composite and $M$ is the moisture in percent by weight; and (2) an empirical equation to estimate the HT-degraded "resin-controlled" property ( $\left.P_{H T}\right)$ is as follows:

$$
P_{H T} / P_{O}=\left\{\left(T_{g W}-T\right) /\left(T_{g 0}-T_{0}\right)\right\} 1 / 2
$$

where $P_{0}$ is the composite "resin-controlled" property at reference conditions, $T$ is the use-temperature, and $T_{0}$ is the temperature at which $P_{0}$ was measured.

The glass transition temperature of the dry comp.site $\left(T_{g g}\right)$ was determined experimentally to be about $230^{\circ} \mathrm{F}$ for both TFT/E and TFT/P composites. Using $T_{g o}=230^{\circ} \mathrm{F}$ and $M=2$-percent in equation (1), the glass $230^{\circ} \mathrm{F}, T_{\mathrm{gW}}=193^{\circ} \mathrm{F}, \mathrm{T}=120^{\circ} \mathrm{F}$ (test temperature), and $\mathrm{T}=70^{\circ} \mathrm{F}$, go the HT-degraded ratio for "resin controlled" composite properties $\left(P_{H T} / P_{0}\right)=$ 0.68 . This is the required value to determine the degree of hygrothermal degradation for the three different conditions enumerated previously.

Comparisons of the tension, compression, and interlaminar shear strengths for the TFT/E Winding Pattern 1 are shown in figure 12 in bar-chart form. similar comparisions for the TFT/E Winding Pattern 2 are shown in figure 13 and for the TFT/P Winding Pattern 2 in figure 14 . The agreement between measured data and predicted results is excellent. In addition, the predicted HT-degraded properties are somewhat smaller than the experimental data except for the interlaminar shear, figure 14, for which no adequate explantation is available as of this writing. Important conclusions from the strength predictions and comparisons area; (1) the concepts/equations developed previously for hygrothermal effects are applicable to TFT/E and TFT/P laminates as well, (2) the predicted HT-degraded properties for tensile and compressive strengths for the TFT-composites are conservative as compared witil measured data. This is significant because using the HT-degraded properties for design allowables should lead to conservative designs, and (3) the ply stress influence coefficients are an effective means to determine laminate strengths when only a minimum of measured data is available.

\subsection{Fatigue Life}

Fatigue life $\left(S_{N}\right)$ of composites was predicted using the empirical equation described in reference 9 . This empirical equation, expressed here in slightly different form to account for laminate degraded strength as determined previously, is as follows:

$$
S_{N} / S_{1}=1.0-B \log N
$$


where $S n$ cienoies the fatigue life for $N$ cyc?es, $S_{1}$ denotes the static strength which includes HT-degradation and $N$ denotes the number of fatigue cycles. The coefficient $B$ depends on the composite system and the dominant fracture mode. For longitudinal fracture in fiberglass composites, $B$ is about 0.13 ( $r$ ef. 9). Obviously, this coefficient can readily be adjusted to obtain better correlation between experimental data and predicted results, Using $B=0.13$ in equation (3) and respective strengths from figures 12 and 13, the predicted fatigue life curves are plotted: (1) in figure 15 for TFT/E Winding Pattern 1, (2) in figure 16 for TFT/E Wiriding Pattern 2, and (3) in figure 17 for TFT/E Winding Pattern 1 and different R-ratios.

The predicted fatigue results are in good agreement with the dry data for all the cases in figures 15 to 17. The predicted curves underestimated the fatigue life for both dry and hygrothermal data at high fatigue cycles $\left(10^{6}\right.$ cycles and greater). The HT-degraded curve over-estimated the fatigue life of the TFT/E Winding Pattern 1 composite especially at low fatigue cycles ( $10^{6}$ and lower), figure 15 . A higher value for the $B$ coefficient would need to be used to obtain better correlation for the hygrothermal case. It appears from the experimental data in figures 15 through 17 that a bilinear fit would be more appropriate. This can be done by using two different values for the $B$ coefficient in equation (3), one for the range where $N$ is less or equal to $10^{6}$ cycles, and a smaller one for the range where $N$ is greater than $10^{6}$ cycles.

The significant conclusion from the fatigue life prediction and comparisons is that the fatigue life of TFT composite laminates can be adequately predicted for lives up to $10^{6}$ cycles, using the recently developed hygrothermomechanical theory and life/durability procedures, This conclusion/finding should lead to considerable reduction in experimental effort for determining the fatigue life of TFT composites for structurai applications up to $10^{6}$ cycles, however selective testing for higher numbers of cycles may still be necessary.

Taken collectively, the hygrothermal analysis, results and comparisons described herein demonstrated that: (1) composite mechanics can be used effectively to analyze and design TFT composite structural components, (2) combination of conposite mechanics with limited experimental data can be a reliable and cost-effective way to characterize new composite system, and (3) the methodology is available for the analysis and preliminary design of TFT composite structural components in hygrothermomechanical environments.

\subsection{CONCLUSIONS}

The following conclusions are derived from the results and comparisons of the experimental static and cyclic fatigue testing program, as well as the hygrothermomechanical analys is of the TFT (epoxy and polyester (0/90) and $(0 /+45 / 90)$ ) balanced symetric angleplied laminate behavior.

1. The effect of elevated temperature and moisture on the static tensile and compressive strengths of the TFT/E composites is not significant for the conditions studied.

2. The elastic moduli of these angleplied composites a.ce not affected by temperature, humidity, load direction (tension or compression), or by resin type. 
3. Cyclic fatigue data show that moisture and temperature have an effect on the fatigue behavior of the Winding Pattern I TFT $/ E$ composites $(0 / 90)$. However moisture and temperature have no affect on the cyclic behavior of the Winding Pattern 2 TFT/E composites $(0,90 / \pm 45)$.

4. The hygrothermomechanical integrated theory predicts results which are in good agreenent with measured data for elastic and strength properties, while the predicted hygrothermal ply stresses are insignificant compared to corresponding $p$ ? $y$ strength.

5. The life/durability theory adequately predicts the fatigue life of the TFT composites up to $10^{6}$ cycles, though the correlation coefficient may need to be adjusted for the $120^{\circ} \mathrm{F}, 98$-percent relative humidity data for the TFT/E Winding Pattern 1 composite.

6. Collectively, the hygrothermal analysis, results and comparisons demonstrate that the methodology is available for the analys is and preliminary design of TFT composite structural components in hygrothermomechanical environments.

\subsection{REFERENCES}

1. K.E. Hofer, and L.C. Bennett, "Fatigue Testing of L.ow-Cost Fiberglass Composite Wind Turbine Blade Materials, "IITRI-M06066-22, IIT Research Inst itute, Chicago, IL, NASA CR-165566, November 1981. (DOE/NASA/0182-1.)

2. C.C. Chamis, R.F. Lark, and J.H. Sinclair, in "Advanced Composite Materials - Environmental Effects," J.R. Vinson, Editor, ASTM STP-658, pp. 160-192, American Society for Testing and Materials, New York, 1978.

3. 0. Weingart, "Design, Evaluation and Fabrication of Low-Cost Composite 6 lades for Intermediate-Size Wind Turbines, "SCI-81520, Structural Composites Industries, Inc., Azusa, CA, DOE/NASA/0100-1, NASA CR-165342, Sept.
1981.

4. H.W. Gewehr, "Design, Fabrication, Test and Evaluation of a Prototype 150-Foot Long Composite Wind Turbine Blade," R-1574, Kaman Aerospace Corp., Bloomf ield, Conn., DOE/NASA/0600-79/1, NASA CR-159775, Sept. 1979.

5. K.E. Hofer, and J. Jollay, in "Fibrous Composites in Structural Cesign," E. Lenoe, 0.W. Opl inger, and J.J. Burke, Editors, pp. 831-845, Plenum Press, New York: 1980.

6. C.C. Chamis, Comput. Struct. (3) 467-482 (1973).

7. C.C. Chamis, in "Rising to the Challenge of the ' $80 \mathrm{~s}, " \mathrm{pp} \cdot 12-\mathrm{Al}$ to

12-A10, Society of the Plastics Industry, Inc, New York, 1980.

8. C.C. Chamis, "Designing With Fiber-Reinforced Plastics (Planar Random Composites), "NASA TM-82812, 1982.

9. C.C. Chamis, and J.H. Sinclair, "Durability/Life of Fiber Composites in Hygrothermomechanical Environments," NASA TM-82749, 1981. 
TABLF I. - IAYUR SCHEDULE FOR ITET IAMTNATE WINDING PAT"IERNS

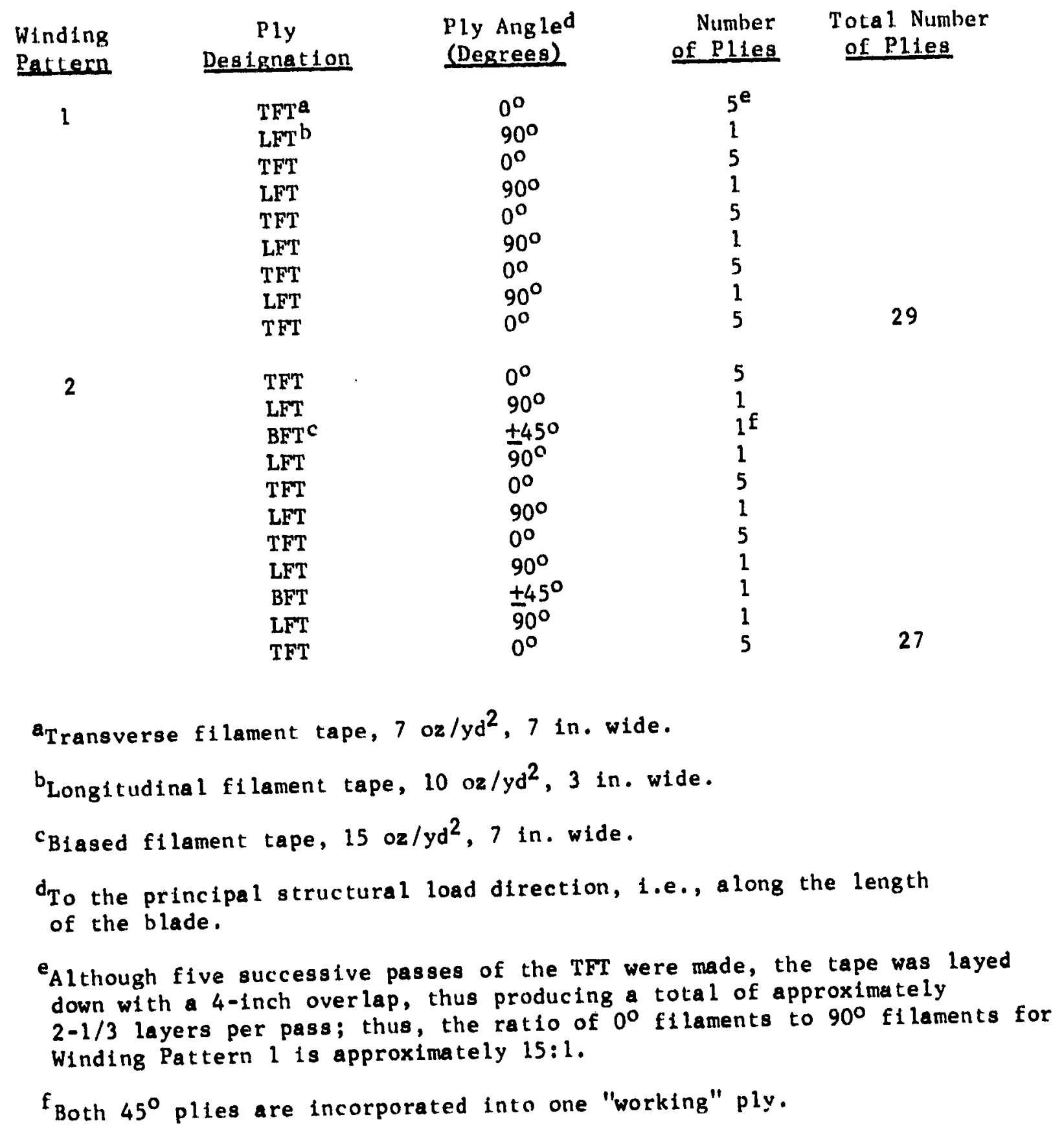


STATIC TESTS

\begin{tabular}{|c|c|c|c|c|c|c|}
\hline \multirow[b]{2}{*}{ MaLerial Type } & \multirow{2}{*}{$\begin{array}{l}\text { Winding } \\
\text { Pattern }\end{array}$} & \multirow[b]{2}{*}{ Preconditioning } & \multirow{2}{*}{$\begin{array}{c}\text { Test } \\
\text { Conditions } \\
\end{array}$} & \multicolumn{2}{|c|}{ Minimum Number o } & \\
\hline & & & & Tension & Compression & Shear \\
\hline TFT/epoxy & 1 & drya & $d r y$ & 5 & 5 & 5 \\
\hline & & wet ${ }^{b}$ & wet & 5 & 5 & 5 \\
\hline & 2 & dry & dry & 5 & 5 & 5 \\
\hline & & wet & wet & 5 & 5 & 5 \\
\hline TFT/polyester & 2 & dry & $\mathrm{dry}$ & 5 & 5 & 5 \\
\hline & & wet & wet & $.5 \ldots$ & 5 & 5 \\
\hline
\end{tabular}

FATIGUE TESTS

Test Conditions

Number of Specimens Fer $R^{C}$ Ratio

Material Type Temperature/Humldity $\quad \underline{R}=0$ R=-0.1 $\underline{R=-0.25} \quad \underline{R=-0.5} \quad \underline{R=-1.0}$

TFT/epoxy;
Winding Pattern
1

$70^{\circ} \mathrm{F} / 50 \% \mathrm{RH}$

$120^{\circ} \mathrm{F} / 98 \% \mathrm{RH}$

128

$5 \quad 5$

$$
1
$$

TFT / epoxy;

$70^{\circ} \mathrm{F} / 50 \% \mathrm{RH}$

$120^{\circ} \mathrm{F} / 98 \% \mathrm{RH}$

5

$\begin{array}{llll}8 & 5 & 5 & \\ 5 & 5 & 5 & 5\end{array}$

Winding Pattern

2

TFT / polyester;

Winding Pattern

$70^{\circ} \mathrm{F} / 50 \% \mathrm{RH}$

$120^{\circ} \mathrm{F} / 98 \% \mathrm{RH}$

12

55

5

$5 \quad 5$

2

$$
5
$$

5

5

5

5

a Dry $=70^{\circ} \mathrm{F}$, Relative Humidity (KH) $=50 \%$.

${ }^{b}$ Wet $=120^{\circ} \mathrm{F}, \mathrm{RH}=98 \%$ for 500 hours.

c $R=$ Ratio of minimum stress per cycle to maximum stress per cycle.

Epoxy resin components - DER-332 with RD-2 reaclive diluent and Tonox 6040 hardener.

Polyester resin components - Polylite-A27623 catalyzed with cumenehyperoxide and Percodox $16 \mathrm{~N}$.

A thixotropic additive ( $1.5 \%$ Cab-o-S11) was mixed with both resins to provide the thickened resin used for fabrication of the $60-\mathrm{ft}$. blades. This additive was included in the resin system to control resin flow during blade fahrication. 
TABLE IIT. - SUMMARY OF STATIC TEST RESULTS

ORIGINAL PATIE IS
OF POOR QIJALITY

\begin{tabular}{|c|c|c|c|c|c|}
\hline Materiala & Load Type & $\begin{array}{l}\text { Material } \\
\text { Condition }\end{array}$ & $\frac{\text { Strength }}{\text { ksi }}$ & $\frac{\begin{array}{c}\text { Modulus } \\
\text { of Elasticity }\end{array}}{10^{6} \text { ps }}$ & $\begin{array}{l}\text { Poisson's } \\
\text { Ratio }\end{array}$ \\
\hline \multirow[t]{6}{*}{ A } & \multirow[t]{2}{*}{ Tension } & $\operatorname{RTD}^{\mathrm{b}}$ & 67.2 & 4.63 & 0.284 \\
\hline & & wet ${ }^{c}$ & 69.0 & 4.27 & 0.243 \\
\hline & \multirow[t]{2}{*}{ Compression } & RTD & 55.6 & 4.61 & 0.300 \\
\hline & & wet & 55.1 & 4.49 & -- \\
\hline & \multirow[t]{2}{*}{$\begin{array}{l}\text { Inter laminar } \\
\text { Shear }\end{array}$} & RTD & 6.3 & -- & -- \\
\hline & & wet & 10.8 & $-\cdot$ & -- \\
\hline \multirow[t]{6}{*}{ B } & \multirow[t]{2}{*}{ Tension } & RTD & 59.9 & 3.85 & 0.312 \\
\hline & & wet & 56.0 & 3.44 & 0.331 \\
\hline & \multirow[t]{2}{*}{ Compression } & RTD & 48.6 & 3.67 & 0.318 \\
\hline & & wet & 51.9 & 4.06 & -- \\
\hline & $\begin{array}{l}\text { Inter laminar } \\
\text { Shear }\end{array}$ & RTD & 7.2 & $-\cdot$ & $-\cdot$ \\
\hline & & wet & 10.6 & $-\cdot$ & -- \\
\hline \multirow[t]{6}{*}{ C } & \multirow[t]{2}{*}{ Tension } & RTD & 64.7 & 3.64 & 0.281 \\
\hline & & wet & $63.9^{d}$ & 3.81 & 0.299 \\
\hline & \multirow[t]{2}{*}{ Compression } & RTD & 49.7 & 4.28 & 0.252 \\
\hline & & wet & 48.2 & 4.11 & 0.259 \\
\hline & \multirow{2}{*}{$\begin{array}{l}\text { Inter laminar } \\
\text { Shear }\end{array}$} & RTD & 10.5 & $-\cdot$ & $\cdots$ \\
\hline & & wet & 9.2 & -- & $\cdots$ \\
\hline
\end{tabular}

\footnotetext{
a Material $A=$ "Inding Pattern 1 TFT/E composite. Material $B=$ Winding Pattern $2 \mathrm{TFT} / \mathrm{E}$ composite. Material $C=$ Winding Pattern 2 TFT $/ P$ composite.

b RTD = room temperature dry $\left(70^{\circ} \mathrm{F}\right)$, and $50 \%$ relative humidity.

c West $=120^{\circ} \mathrm{F}$ and $98 \%$ relative humidity for 500 hours.

d Additional information at 4,000 hours exposure indicetes that the tensile strength drops to $46.4 \mathrm{i}: \mathrm{s} 1$.
} 


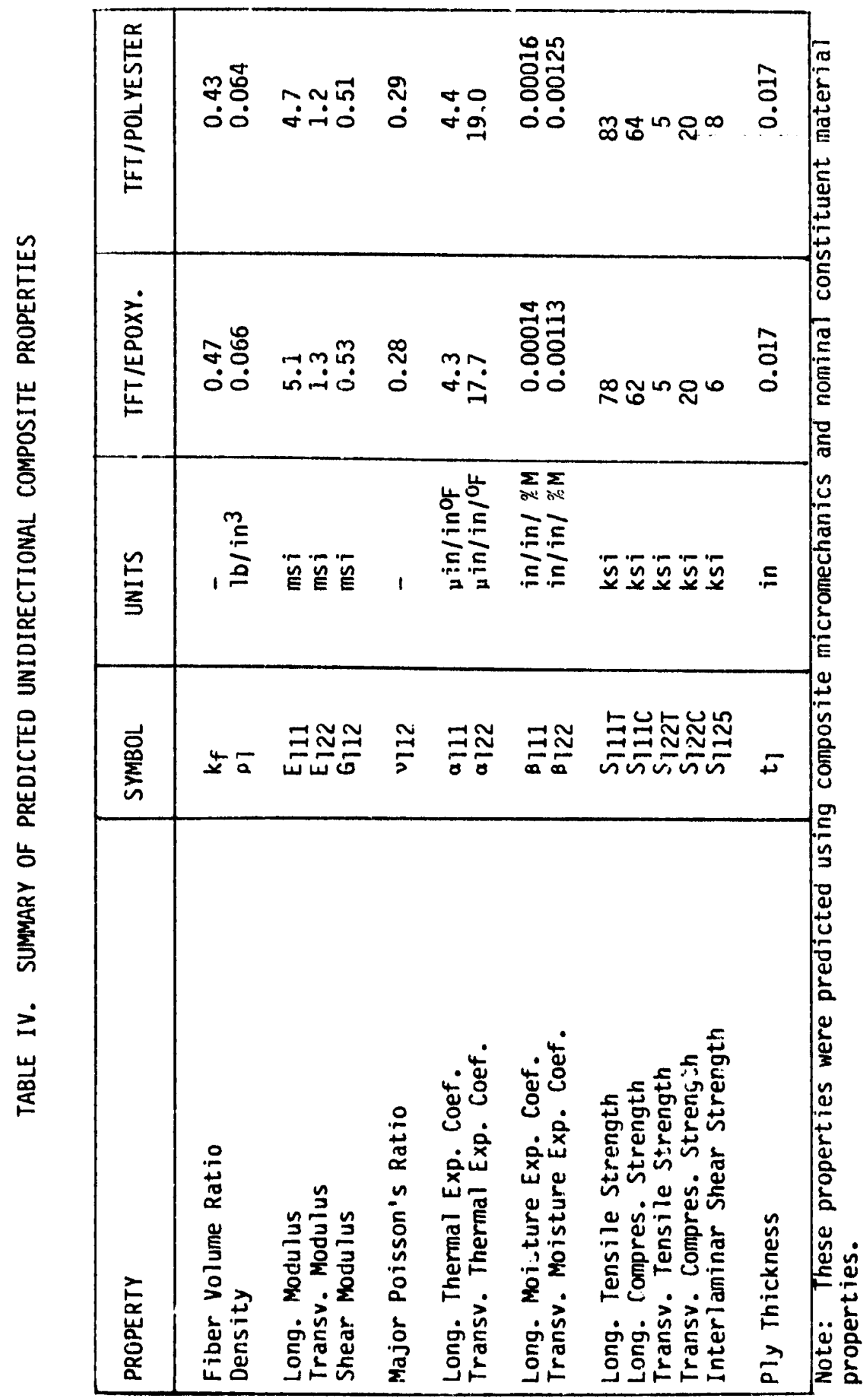




$$
\text { CH Pated at }
$$

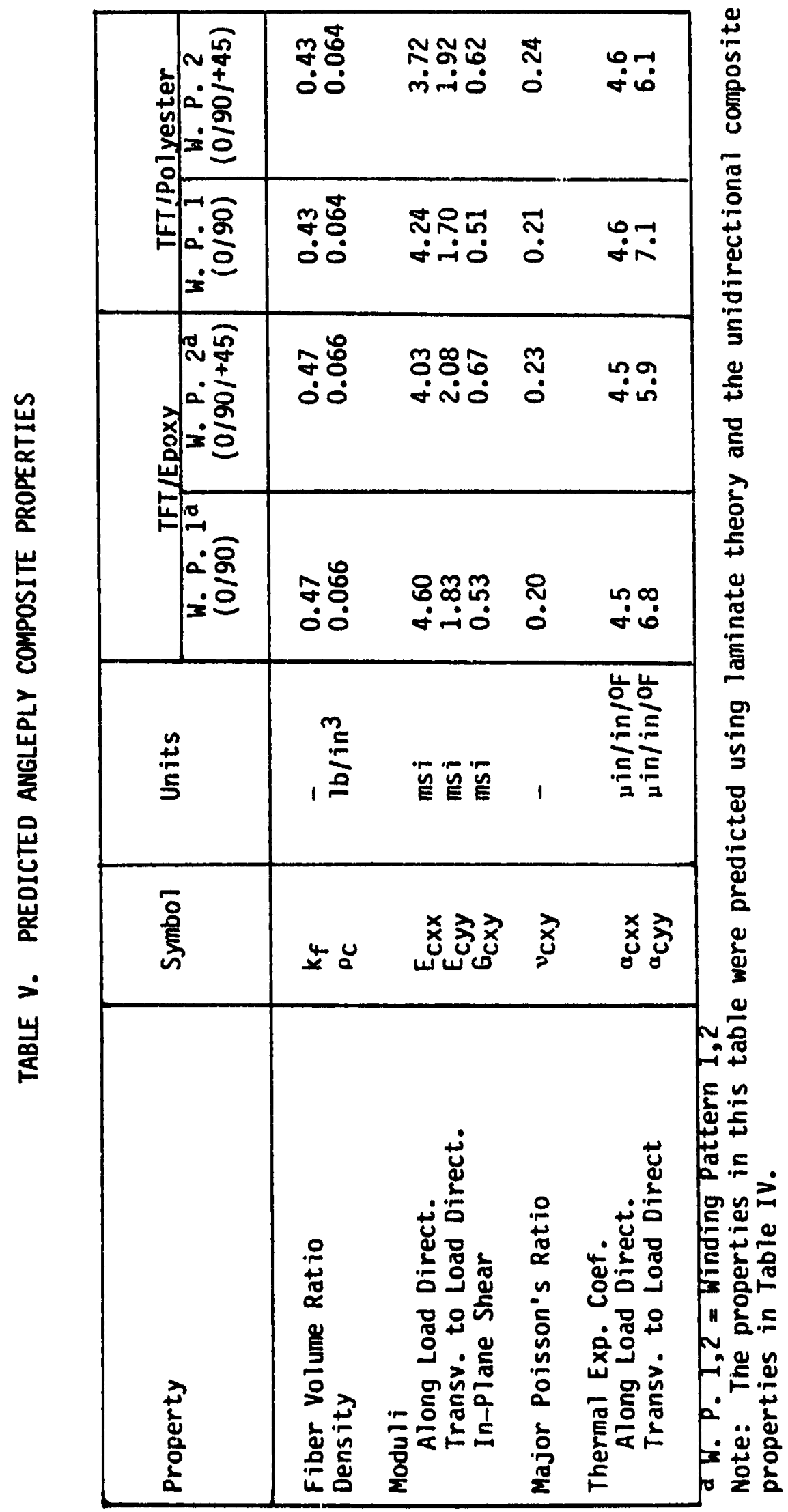




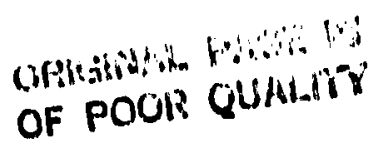

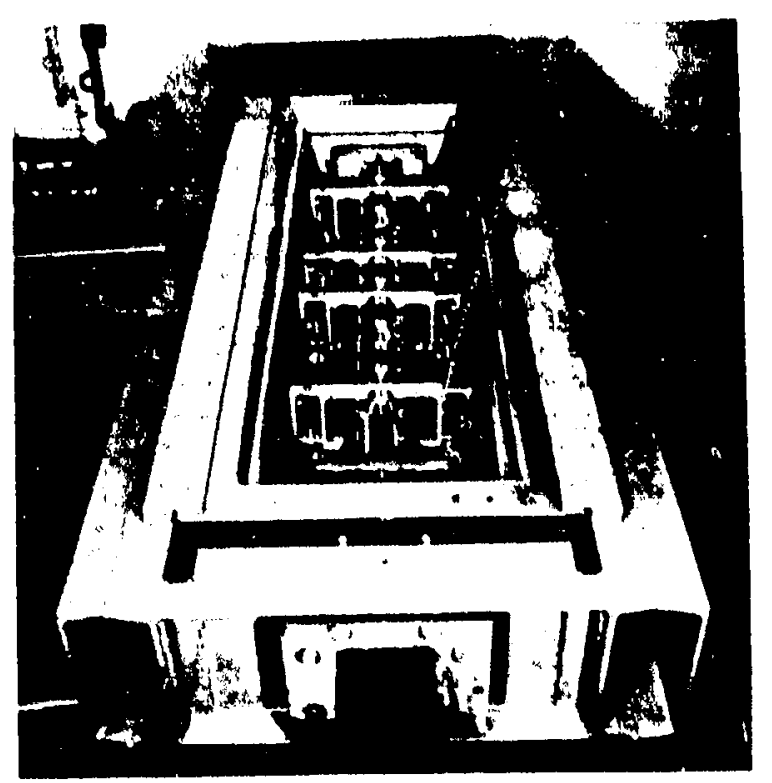

Higure 3. - Environmental test chamber for multiple specinen testing.

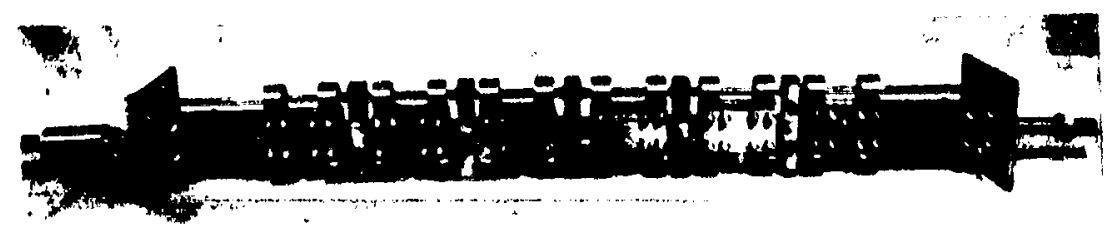

Bigure 4 Multiple sperimen leadiny chain. 
ORIGINAR

OF POOI?

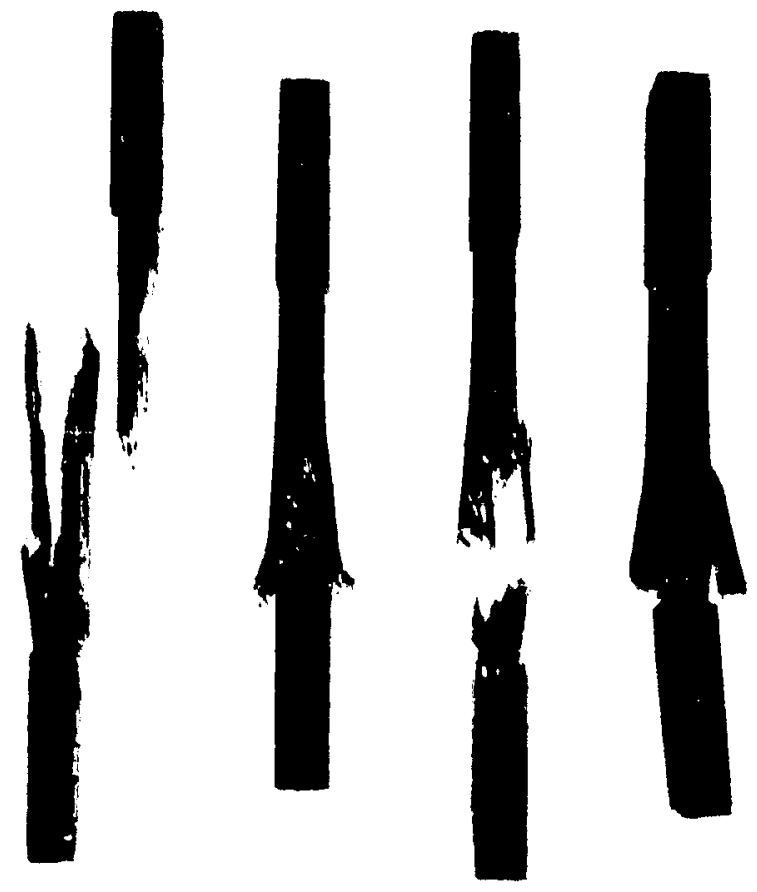

Figure 7. - Typical fracture appearance of winding pattern no.2 specimens subjected to full-rever sed cyclic fatigue loading.

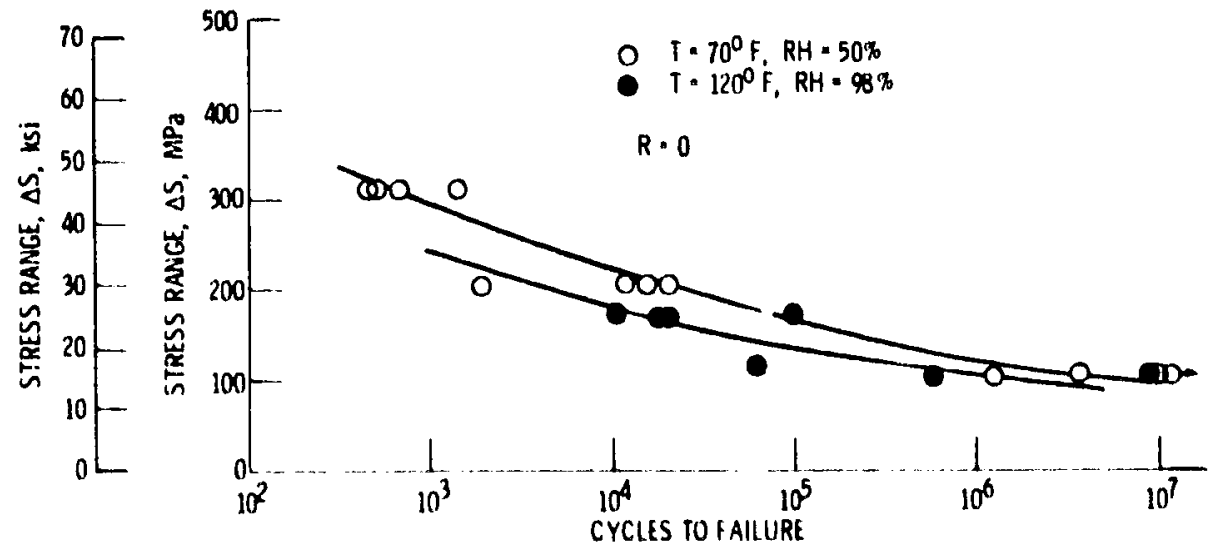

Higure 8. - S-N fattgüe lite diagram for winding pattern ITF T/LPOXY composites. 


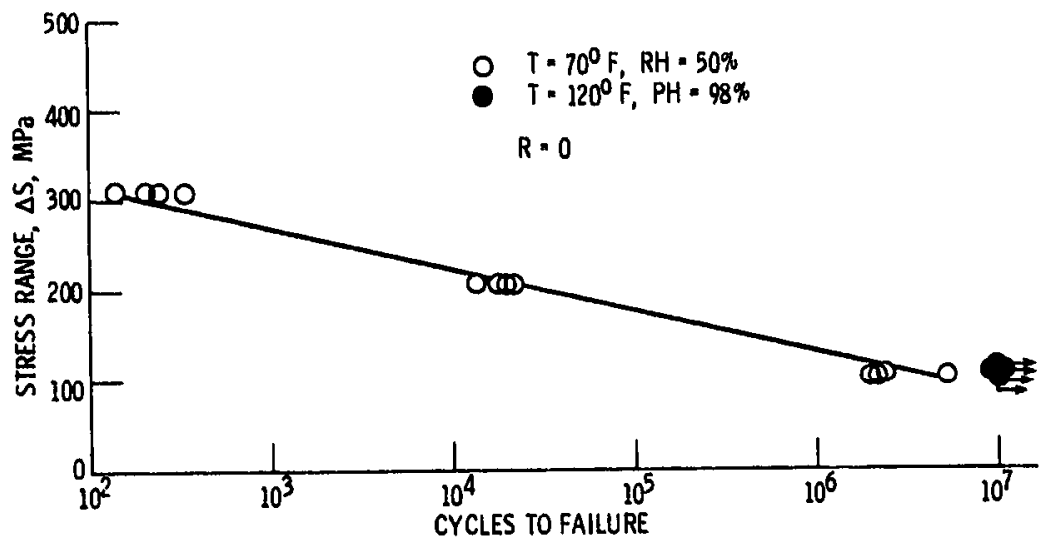

Figure 9. - S-N fatigue life diagram for winding pattern 2 TFT/EPOXY composites.

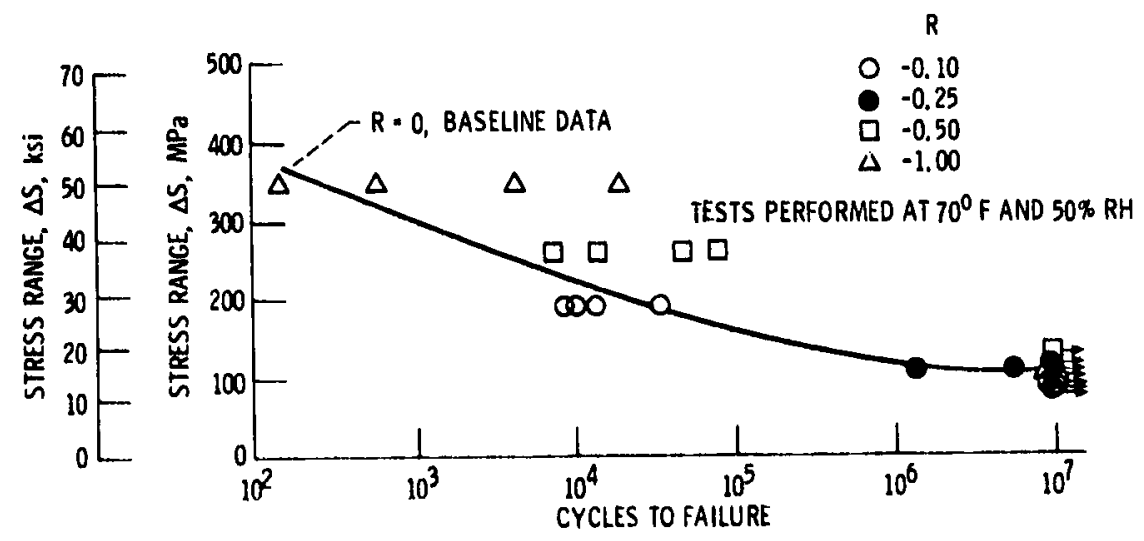

Figure 10. - Effect of mean stress on fatigue endurance for winding pattern I TFTIEPOXY composites. 

ORIGINAL BASE IS

OF POOR Gising

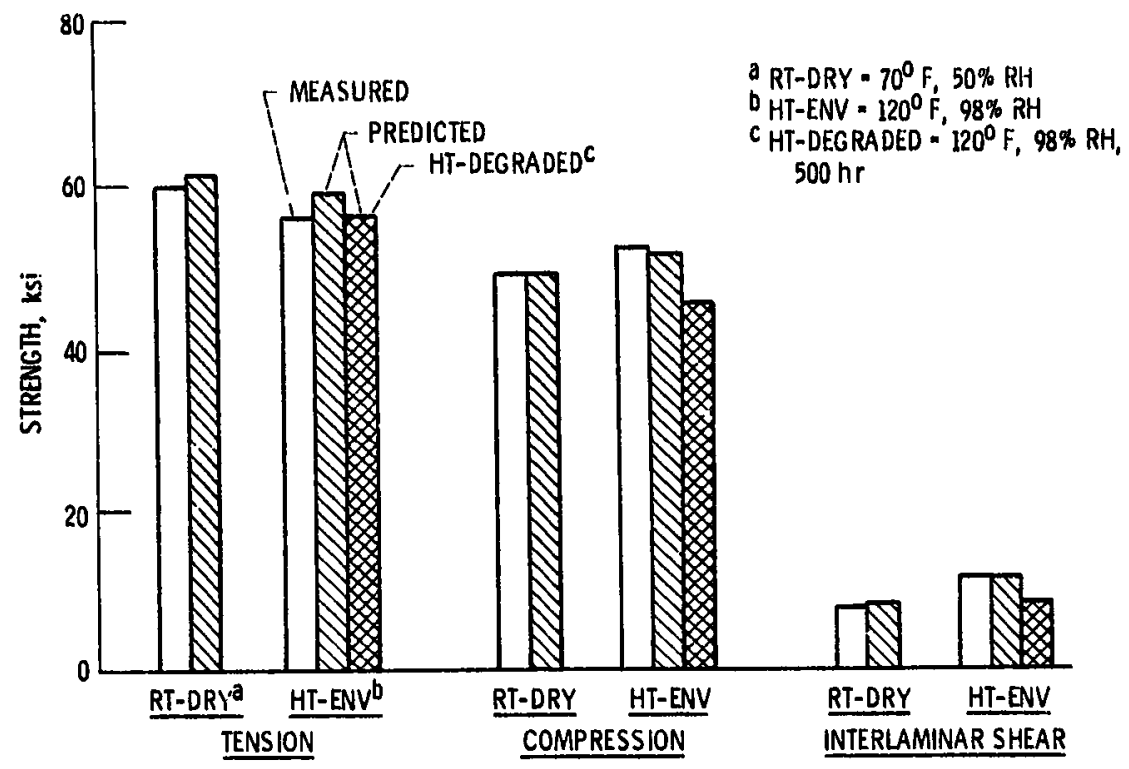

Figu re 13. - Strength comparisons - TFTIEPOXY winding pattern $210 \% 90 \% \pm 45 \%$.

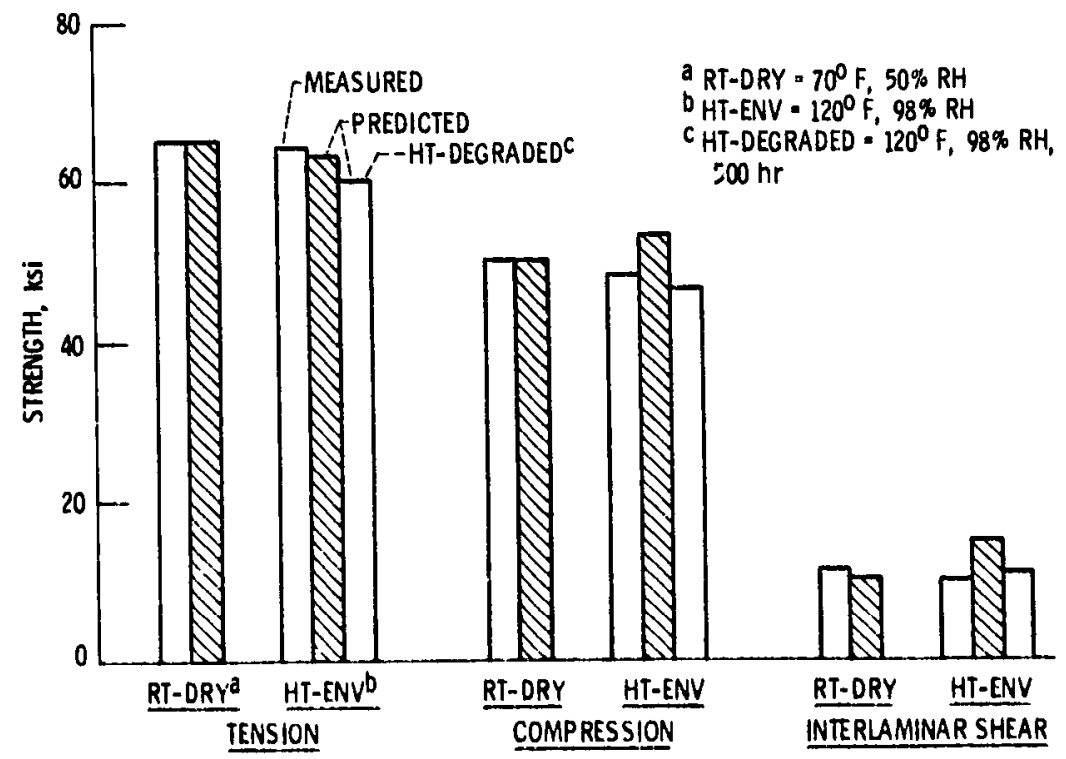

Flaure 14. - Strength comparisons - TFTpolyester winding pattern $210990^{\circ}+45^{\circ}$. 


\section{ORIGINAL PAQE IS \\ OF POOR QUALITY}

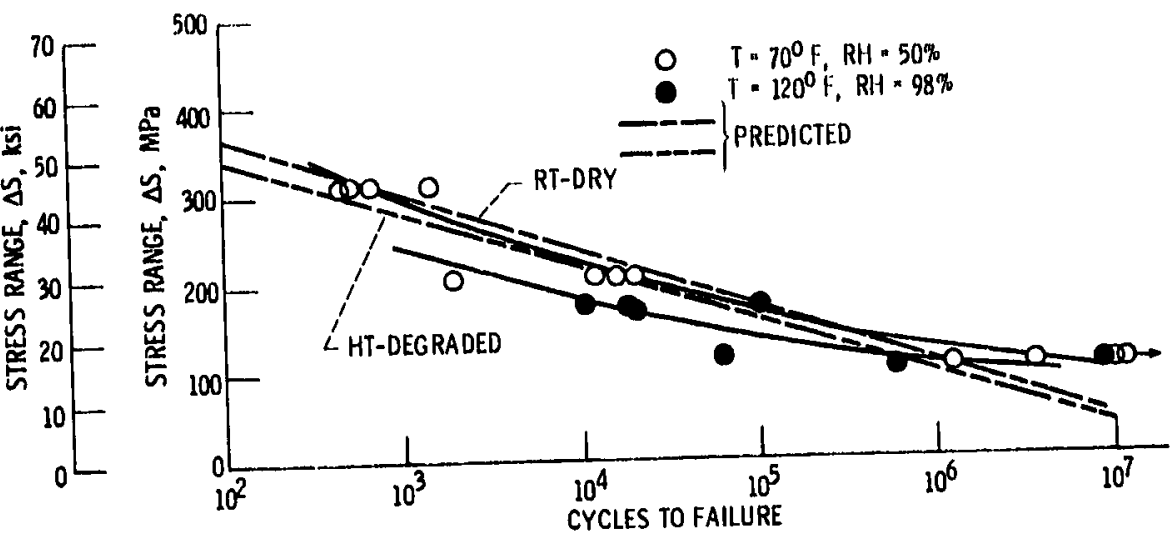

Figure 15. - Comparison of S-N fatigue life diagram for winding pattern I TFT/EPOXY composites $(R=0)$.

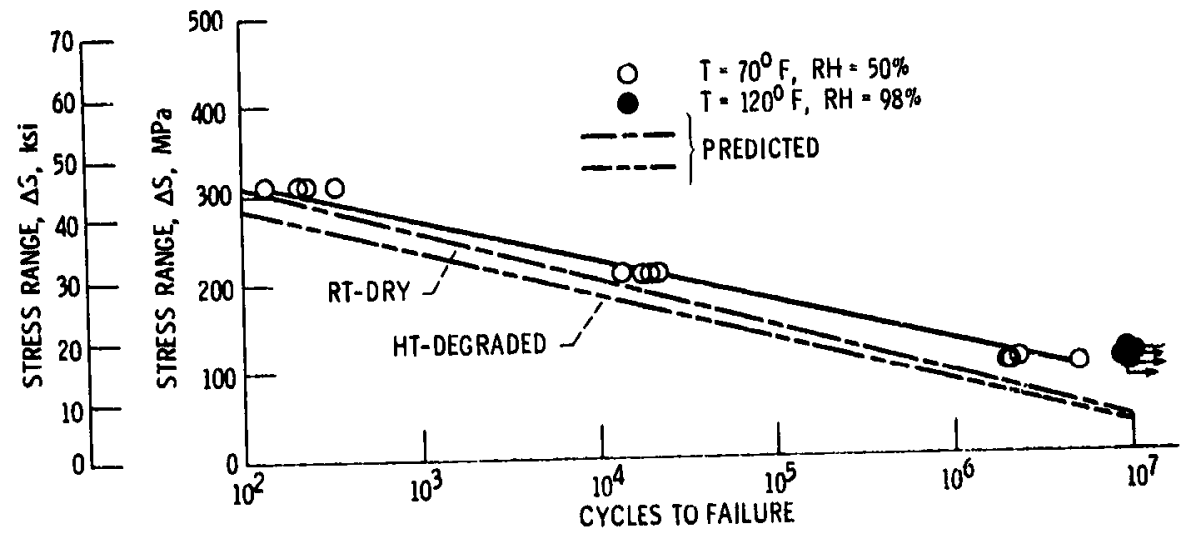

Figure 16. - Comparison of S-N fatigue llfe diagram for winding pattern 2 IFT/EPOXY composites ( $R=0$ ).

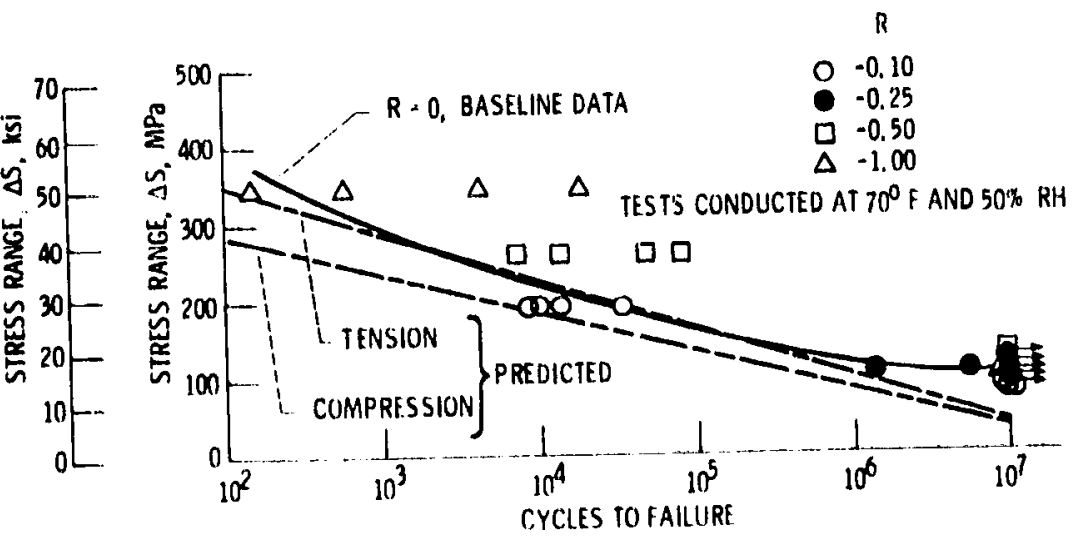

Figure 17. - Comparison of effect of mean stress on fatigue endurance for winding pattern I TF TEPOXY composites 